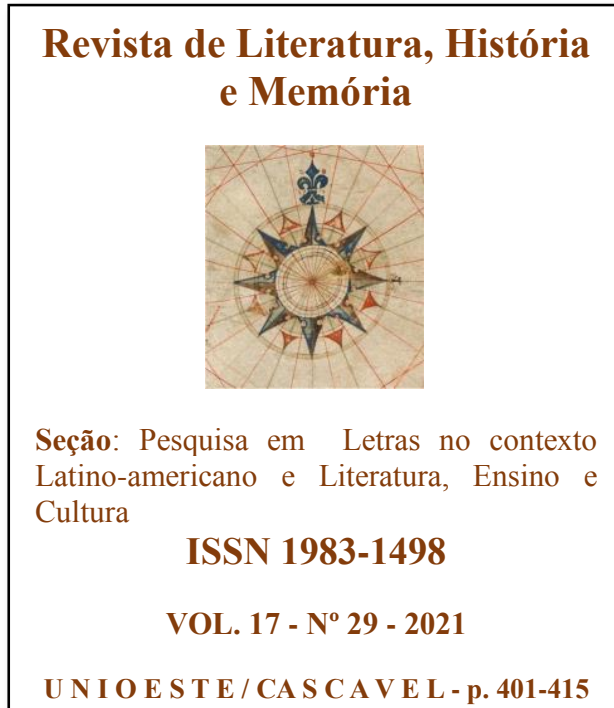

\section{A ÚLTIMA OFERENDA: REMINISCÊNCIAS DOS PAIAGUÁ (EUVEVI) EM JOSEFINA PLÁ}

The last offer:

reminiscences of paiaguá (euvevi) in Josefina Plá

\author{
Débora Cota ${ }^{1}$ \\ Catiane da Costa Reas ${ }^{2}$
}

RESUMO: Desde a colonização, os povos ameríndios têm sofrido com o apagamento ou mesmo a invisibilização de suas culturas. Lançar luz sobre suas existências é colocar em diálogo passado, presente e futuro. Tendo em mente essa breve e importante consideração, neste trabalho, apresenta-se uma breve análise sobre um texto que foi publicado poucos dias após a morte da escritora Josefina Plá (Espanha 1909 - Paraguai 1999), pelo jornal Correo Semanal de Assunção. La última ofrenda payagua é um texto no qual Plá escreveu sobre os paiaguá, comunidade ameríndia considerada extinta após a guerra do Brasil, Argentina e Uruguai contra o Paraguai. Assim, este estudo tem como finalidade entender a importância e a relação do trabalho de Josefina Plá com a cultura ameríndia. Mais especificamente, o trabalho se concentra em compreender de que maneira a autora recuperou reminiscências da estética paiaguá em seus trabalhos com a serigrafia e a cerâmica e que servem como arquivo desta cultura. $L a$ última ofrenda payagua (1999) é um dos textos em que se percebe a tentativa de Plá para recuperar uma cultura que é irrecuperável, mas sobre a qual a autora procura afastar a escuridão imposta a ela na contemporaneidade.

PALAVRAS-CHAVE: Josefina Plá; Paiaguás; Paraguai; Reminiscências.

ABSTRACT: Since colonization, the Amerindian peoples have suffered with the extinction os devastation of their culture. To put light on their existence is to put past, present and future in dialogue. Bearing in mind that brief and important consideration, in this work, a brief analysis is presented about a text the was published a few days after the death of the writer Josefina Plá (Spain 1909- Paraguay 1999) by the newspaper Correo Semanal de Assunción. The last payaguá offering is a text in which Plá wrote about the Payagua, an Amerindian community considere extinct after the war between Brazil, Argentina and Uruguay against Paraguay. Thus, this study aims to understand the importance and relationship of Josefina Plá's work on Amerindian culture. More specifically, the work focuses on understanding how the author has recovered reminiscences of Payagua aesthetics in her works with silk-screen printing and ceramics and tha they serve as an archive of this culture. The last payaguá offering (1999) is one of the texts in which Plá's attempt to recover a culture that is irretrievable, but on which the author tries to remove the darkness imposed on her in contemporary times, is perceived. KEYWORDS: Josefina Plá; Payagua; Paraguay; Reminiscences.

\footnotetext{
1 Doutora em literatura pela Universidade Federal de Santa Catarina (UFSC), com pós-doutorado na Universidade da Califórnia - Berkeley. Docente do Programa de Pós-Graduação em Literatura Comparada da UNILA.

${ }^{2}$ Mestranda no Programa de Pós-graduação em Literatura Comparada da UNILA.
} 


\section{INTRODUÇÃO}

O debate em torno da literatura ameríndia contemporânea latino-americana tem sido um importante espaço, ainda que muito limitado, para que muitas comunidades ameríndias façam com que suas vozes sejam ouvidas. Embora já tenham suas narrativas orais, tem crescido produções literárias escritas pelos próprios ameríndios que divulgam suas visões de mundo. No Brasil, autores como Eliane Potiguara, Kaka Werá Jecupé e Daniel Munduruku estão utilizando a escrita como forma de pôr em evidência conhecimentos sobre a cultura e os costumes de seus povos, que, por muito tempo tiveram suas vozes silenciadas e marginalizadas. Esse silenciamento das culturas ameríndias é decorrente de um violento processo de colonização que deixou feridas profundas e ainda não cicatrizadas em todo o continente americano.

Há muitas comunidades que continuam silenciadas e esquecidas, principalmente, aquelas dizimadas nos constantes processos de apagamento da cultura ameríndia na América Latina. Uma dessas comunidades é a dos paiaguá, que, segundo alguns pesquisadores (COSTA, 2003 e JESUS, 2015) é o povo que deu origem ao nome do país que hoje conhecemos como Paraguai. Trata-se de um povo canoeiro que vivia no Rio Paraguai entre Assunção e Cuiabá no Mato Grosso do Sul e que foram considerados completamente extintos após a guerra do Brasil, Argentina e Uruguai contra o Paraguai, no final do século XIX.

Considerando as discussões que atravessam os debates contemporâneos sobre as alteridades na América Latina, o trabalho propõe apresentar uma análise sobre o texto $L a$ última ofrenda payagua, de Josefina Plá, publicado em 14 de janeiro 1999 no jornal Correo Semanal em Assunção, apenas três dias após falecimento da autora. Nesse texto, Josefina Plá fala sobre como teve contato com a estética paiaguá e como esse contato influenciou seu trabalho com a serigrafia e a cerâmica. É um texto que, assim como as muitas pesquisas realizadas pela autora sobre as comunidades nativas paraguaias, reivindica a 'memória cultural' (ASSMANN, 2016) do Paraguai e reconhece as alteridades do país como pertencentes a esta memória.

Dessa maneira, pretende-se por meio de uma análise do texto de Josefina Plá sobre os paiaguá verificar como a autora entendia as questões referentes às culturas locais e seu contato com os colonizadores. Também, procura-se entender como a autora trabalha e dialoga com os desenhos dos paiaguá na produção de artes plásticas, como a serigrafia e a cerâmica e ainda, como-se deu o processo de 'arquivamento' (ASSMANN, 2016) da memória da arte paiaguá no trabalho desta importante estudiosa da cultura paraguaia. 


\section{REMINISCÊNCIAS NO BARRO}

No já clássico texto, Teses sobre o conceito de historia (1987) Walter Benjamim discute e sintetiza a relação entre história e dominação, fatores que, interligados criam narrativas que oferecem glórias e louvores aqueles apontados como vencedores na história. Isso se dá porque as narrativas foram criadas a partir de uma perspectiva que tem empatia pelo vencedor, e que marginaliza os vencidos. Mas, nos ensina Walter Benjamin: "Articular historicamente o passado não significa conhecê-lo 'como ele de fato foi'. Significa apropriarse de uma reminiscência, tal como ela relampeja no momento de um perigo" (BENJAMIN, 1987, p.224). Com isso, o autor nos ensina tanto sobre a presença do passado no presente, quanto sobre a incapacidade de o acessarmos totalmente. Diante de tal impossibilidade, nos resta portanto, "Escovar a história a contrapelo" (BENJAMIN, 1987, p. 225). Para o autor, trabalhar em tal perspectiva é a tarefa do historiador contemporâneo que percebe no presente o apelo das vozes que emudeceram no passado. A ele cabe propor novas narrativas em torno do passado nas quais vozes marginalizadas ou silenciadas sejam ouvidas.

Leitor e tradutor de Walter Benjamin, o italiano Giorgio Agamben (2009) nos diz que ser contemporâneo é manter o olhar no presente e perceber dentro da escuridão do presente os fatos do passado como se eles saltassem neste momento e arrastassem o espectro do passado até hoje; ser capaz de entender as fraturas do tempo presente, e nos mantendo nessa fratura, perceber como o escuro do presente projeta suas sombras sobre o passado. Pois, o tempo contemporâneo é como uma junção do tempo passado, presente e futuro e o passado aparece em um momento de perigo no presente como alerta para mostrar mais da nossa época do que do tempo passado. Assim, a condição contemporânea é fundamentalmente uma ideia paradoxal, de perceber as ruínas do passado e mesmo querendo voltar, estar, inevitavelmente, fadado a ir ao futuro incerto. Ao tratar do termo 'contemporaneidade', Agamben afirma que:

contemporâneo é aquele que mantém fixo o olhar no seu tempo, para nele perceber não as luzes, mas o escuro [...] Isso significa, se voltamos agora à nossa tese sobre o escuro da contemporaneidade, que perceber esse escuro não é uma forma de inércia ou de passividade, mas implica uma atividade e uma habilidade particular que, no nosso caso, equivalem a neutralizar as luzes que provêm da época para descobrir as suas trevas, o seu escuro especial, que não é, no entanto, separável daquelas luzes. (AGAMBEN, 2009, p.62-63).

Ademais, o contemporâneo é um apelo de explosão do continuum do tempo que percebe que assim como o futuro está em aberto, o passado também está e lança um apelo até 
o tempo presente. Assim como Agamben (2009) levanta a questão da luz que não chega, Benjamin pontua que "assim, como as flores dirigem sua corola para o sol, o passado, graças a misterioso heliotropismo, tenta dirigir-se para o sol que se levanta no céu da história" (BENJAMIN, 1987, p.224). Neste sentido, devemos ficar atentos as essas transformações das narrativas históricas que podem ser reatualizadas a qualquer momento de acordo com as novas descobertas sobre o passado que era considerado morto. É fato que vivemos entre vários tempos, quem passa por uma cidade grande, por exemplo, consegue perceber essa justaposição apenas observando a concomitância de prédios históricos e construções supermodernas. A incompletude deles, permite portanto, que eles estejam em movimento.

É com base nesta ideia que podemos afirmar a perspectiva contemporânea do trabalho de Josefina Plá. Ao estudar a cultura paraguaia, a autora se depara com o escuro em relação à sistematização da história das produções culturais no Paraguai. Sua obra artística, literária e teórica, portanto, se debruça sobre as alteridades ao perceber o passado que encontra-se em aberto no presente. La última ofrenda payagua (1999) é um dos textos em que, neste sentido, se percebe a tentativa de Plá para recuperar uma cultura que é irrecuperável, mas sobre a qual a autora procura afastar a escuridão imposta a ela na contemporaneidade.

As comunidades nativas paraguaias, sofreram não só com o processo de colonização como também com as inúmeras guerras pelas quais passou o país. Assim, a importância do trabalho de Josefina Plá decorre justamente de sua percepção quanto à latência de uma cultura que deixou rastros na cultura paraguaia. A autora ilumina a cultura paiaguá através do arquivamento, da inscrição de tal cultura em sua produção. Resgata, assim, um trauma sofrido pela sociedade paraguaia decorrente de uma forma mais ampla, de todo o processo de colonização e também com a Guerra da Tríplice Aliança. Inspirada nos motivos paiaguá, em 1954, Josefina decora pratos de argila de diversos tamanhos utilizando-se de técnicas como o engobe e o esgrafiado. No texto La última ofrenda payagua (1999) a autora afirma que o sucesso do trabalho com os motivos paiaguá a levou a ampliar o repertório tratando também de outras comunidades nativas e também da formação da sociedade paraguaia. Josefina Plá, também afirma em seu texto que fez mais de mil e quinhentos cacharos y cacharitos com motivos ameríndios. (1999, p.17)

Assim sendo, a preocupação de Plá com a memória cultural do Paraguai faz com que elementos, como os desenhos dos paiaguá, tragam à luz do presente o 'índice misterioso' que estava fadado ao esquecimento, "pois irrecuperável é cada imagem do passado que se dirige ao presente, sem que esse presente se sinta visado por ela" (BENJAMIN, 1987, p. 221). 


\section{PAIAGUÁ: BREVE HISTÓRIA}

Embora tenha sido bastante comum na formação das sociedades latino-americanas uma visão eurocêntrica na construção das narrativas, desde o século passado acentuou-se o aparecimento de vozes de grupos marginalizados que reivindicam o direito à história e à memória, sem a visão estereotipada que foi disseminada até então. Tais estereótipos, na literatura, no caso dos ameríndios, foram construídos, principalmente, no Romantismo, quando os autores buscavam constituir uma identidade nacional a partir de uma literatura indianista que precisava, a qualquer custo, aproximar a cultura latino-americana da cultura europeia. Neste sentido, na literatura romântica brasileira encontramos personagens ameríndios idealizados, muitas vezes apresentados com 'qualidades' próprias do herói branco, guerreiro e europeu. Assim, o indígena real, sua cultura, costumes e diferenças entre as comunidades foram ignoradas, a ponto de negar a diversidade cultural brasileira.

$\mathrm{Na}$ literatura paraguaia, apesar de uma língua indígena figurar como língua oficial, tradicionalmente, as culturas ameríndias não possuem um lugar de acolhimento. Sua cultura, com raras exceções, é marginalizada e renegada a um papel de lendas, invenções fantasiosas ou mesmo irreais, uma vez que as narrativas, muitas vezes revelam visões de mundo distantes da cultura ocidental.

Desde a colonização, a história do povo paraguaio é marcada por diversos conflitos que contribuíram na constituição do país. Entre eles, muitos conflitos tiveram como resultado o desaparecimento de povos autóctones e com eles, línguas, culturas e histórias. Dentre os conflitos mais importantes está a guerra do Brasil, Argentina e Uruguai contra o Paraguai (1864-1870), conhecida no Brasil como a Guerra da Tríplice Aliança, que deixou a sociedade paraguaia quase sem homens, considerando que os únicos homens que sobraram ou eram crianças ou eram anciões. Uma das comunidades ameríndias que teve seu desaparecimento definitivo após esta guerra, foi a paiaguá, comunidade que, como já se indicou, provavelmente deu origem ao nome do país.

De acordo com Nauk Maria de Jesus (2015, p.306) os paiaguá, em sua própria língua se denominavam Euvevi que significa gente do rio. Eles ocupavam as terras do Alto Paraguai e dominavam um grande rio, que foi denominado pelos guaranis como Rio de paiaguás. Mais tarde, os europeus transformaram o termo paiaguá em Paraguai e por influência dos guaranis denominaram o povo canoeiro de paiaguá, que era uma forma pejorativa com a qual os guaranis tratavam os Euvevi.

Em geral, os paiaguá armavam emboscadas e surgiam de sangradouros e furnas aos 
gritos embarcados em muitas canoas, com porretes, lanças e flechas que chegavam a medir 25 palmos de comprimento e tinham por hábito desafiar os viajantes. $\mathrm{Na}$ destruição da monção paulista que retornava para São Paulo em 1730, eles surgiram com urros em cinquenta canoas, sendo que em cada uma delas tinha dez a doze índios pintados e emplumados, tendo a cabeça ornada com variedade de penas. Ao final dessa batalha, liderados pelo cacique e vitoriosos, se afastaram para rio em duas linhas e desafiaram os sobreviventes que se refugiaram nas margens (CAMELO, 2002, p. 25).

Em uma breve nota a Revista Trimensal, em 1862, intitulada Notícia que dá o capitão Antonio Pires de Campos do gentio bárbaro que ha na derrota da viagem das minas do Cuyabá e seu recôncavo (1862), o capitão Antonio Pires de Campos conta sobre as várias etnias que encontrou em uma viagem por Cuiabá - MT e sobre como essas etnias poderiam representar perigo para brancos que ousassem passar por seus territórios. Sobre os paiaguá, encontra-se o seguinte comentário:

Os gentios Payaguazes, cujas suas moradas são sempre andarem embarcados e não terem domicilio certo, não mais que como corsários rio abaixo, e acima a ver se tem encontros, aonde fazem, e tem feito grandíssimo damnos aos brancos que navegam ao dito rio Paraguay [...] fazem cruel guerra a outros gentios, e tambem a algumas povoações de castelhanos, que por se livrarem das suas hostilidade, e grande numero de cavalleiro, lhe pagam tributo, levando cada um 4 e 5 cavallos a dextra (CAMPOS, 1862, p. 440441).

Também, assim como outras comunidades nativas, os paiaguá eram acusados de raptar crianças e mulheres que, ou passavam a viver com a comunidade, ou eram libertados mediante um valor em dinheiro para o resgate do cativo. Na nota da Revista Trimensal (1862), o capitão Antonio Pires de Campos fala sobre um assalto paiaguá que "acommetteram duas nossas que roubaram matando a Miguel Antunes Manuel Lobo, e dez escravos levando um menino branco captivo" (1862, p. 440). Nauk Maria de Jesus (2015) narra a história de Domingas Roiz, uma senhora que foi raptada pelos paiaguá e vendida a preço alto em Assunção. A moça tinha entre 18 e 20 anos, era de Lisboa e estava grávida. Seu marido foi morto no assalto e ela passou três meses com os paiaguá.

Conhecidos como temidos piratas do rio Paraguai, os paiaguá tinham as águas do rio como arena de luta. As crônicas dessa época dão conta de que foram registrados dezoito ataques dos paiaguá aos grupos que saíam em explorações pelo rio Paraguai no século XVIII. Existe registro de ataques em comunidades que se instalaram nas proximidades das margens dos rios. Segundo Nauk Maria de Jesus “Alguns dos enfrentamentos partiram dos índios, que 
antes de serem combatidos optaram pelo ataque, como demonstração do "ethos guerreiro" e de que o lugar já estava ocupado" (JESUS, 2015, p. 307). A disputa pelo território é um dos maiores problemas enfrentados até hoje pelos ameríndios da América Latina. Muitas comunidades foram dizimadas por não aceitar os acordos com portugueses e espanhóis e por seguir defendendo suas terras.

A disputa por território e o medo de navegar pelas águas do rio fez com que o governador de São Paulo travasse diversas guerras contra os paiaguá, mas, eles sempre venciam as batalhas por serem experientes e conhecedores da região onde dominavam. Em abril de 1731, o governador de São Paulo, Rodrigo César de Menezes, envia quatrocentos homens em trinta canoas de guerra para combater os paiaguá e é derrotado. Em 1732 solicita apoio ao rei, que neste mesmo ano expede uma ordem régia declarando guerra justa aos paiaguá. Em agosto de 1734 seguiu a expedição com vinte e oito canoas de guerra, oitenta de bagagem e montaria, três balsas que eram casas portáteis armadas sobre canoas, oitocentos e quarenta homens entre brancos, pretos, pardos e mestiços. Foi à primeira derrota dos paiaguá. Após a guerra de 1734, duzentos e sessenta e seis índios foram presos e seiscentos foram mortos. Os indígenas presos foram escravos da sociedade colonial. Após a guerra contra o Paraguai, a comunidade que já estava enfraquecida devido aos diversos ataques que vinha sofrendo, é extinta completamente. (JESUS, 2015, p.311-312)

Da guerra contra o Paraguai, restou uma sociedade destruída, mas também muitos heróis. Muitos são os discursos em torno da guerra que idealizaram os feitos de determinados líderes, como os do ditador Solano Lopes, que o tornou conhecido como o defensor da pátria. Uma nação se constrói a partir de histórias de batalhas e vitórias pelas quais passou, mas quem tem o poder de contar essas memórias sempre impõe suas versões e seus heróis e empurram ao esquecimento todos os grupos subalternos que lutavam. Há sempre um silenciamento quanto às pessoas que foram subalternizadas e enviadas a frente das batalhas, aquelas que derramaram seu sangue em defesa de uma luta que não lhes pertencia. Os paiaguá, que já estavam com uma comunidade enfraquecida devido aos constantes ataques que sofreram tanto do governo brasileiro como do governo paraguaio, após a Guerra da Tríplice Aliança desapareceram por completo. Para Roa Bastos:

Nuestras sociedades que tanto han exaltado los valores del heroísmo patrio, no han sabido nunca tomar conciencia del valor tenaz con que hombres y tribus han intentado defender su territorio y su identidad cultural, hasta derramar la última gota de su ser. No hay prácticamente en el Paraguay una sola tribu que no haya tenido que sufrir su guerra de la tríplice alianza, en la que fue atacada y diezmada por las tres potencias de la invasión territorial, la 
destrucción biológica y la desintegración cultural. ¡Morimos con nuestra tierra! Van gritando en su agonía (ROA BASTOS, 2011, p. 29) ${ }^{3}$.

A diferença do escritor paraguaio, trabalhos e apresentações realizados sobre a guerra contra o Paraguai não costumam tratar da participação dos indígenas. Nos livros brasileiros são enaltecidos os militares do Brasil que comandaram a invasão das terras paraguaias e tratam Solano Lopes com um tirano que colocou toda sua população em risco. $\mathrm{Na}$ historiografia paraguaia, Solano é apresentado como um herói, um mito que defendeu os interesses de seu povo e de sua pátria. Assim, o esquecimento dos mortos é sempre imposto, pois o imaginário de nação se constrói a partir de quem tem o poder de contar as recordações e com quem esse sujeito tem empatia. Para Walter Benjamin (2009) a história sempre foi contada por quem tem empatia com o vencedor. Por trás do esquecimento estão as forças sociais e políticas dos grupos subalternos que lutam por outra visão da história.

Como pesquisadora interessada nas culturas que constituem o Paraguai, Josefina Plá recupera o que sobrou, coleta as reminiscências da cultura paiaguá e as utiliza nas suas produções artísticas como a serigrafia e a cerâmica. Dessa forma, recria a estética paiaguá como mecanismo para jogar luz sobre uma cultura considerada extinta, mas que é de fundamental importância para a cultura do país. Plá lamenta que a comunidade tenha sido tão pouco estudada, e que o pouco que resta sobre eles sejam alguns relatos em crônicas e desenhos encontrados em livros.

\section{A ÚLTIMA OFERENDA}

Não há como negar que a situação de deslocamento de Josefina Plá, tenha contribuído em seu interesse pela diversidade da cultura local. Ela entrega todo seu trabalho à cultura, em suas variadas manifestações desde que chega no país. A comunidade guarani foi sem dúvida uma das mais estudadas por Plá, justamente porque é a comunidade ameríndia mais disseminada no país. Ao chegar ao Paraguai, em 1927, Plá começa sua produção artística, influenciada pelo marido, o paraguaio Andrés Campos Cervera, (conhecido como Julián de la Herrería), que desenvolvia seu trabalho com a cerâmica baseando-se nos motivos mitológicos

\footnotetext{
${ }^{3}$ Nossas sociedades que tanto exaltam os valores do heroísmo pátrio, não tem sabido nunca tomar consciência do valor tenaz com que homens e tribos têm tentado defender seu território e sua identidade cultural, até derramar a última gota de seu ser. Não há praticamente no Paraguai uma só tribo que não deva ter sofrido sua guerra da tríplice aliança, na qual foi atacada e dizimada pelas três potências da invasão, a territorial, a destruição biológica e a desintegração cultural. ¡Morremos com nossa terra! Vão gritando em sua agonia (ROA BASTOS, 2011, p. 29, tradução propria).
} 
da América pré-colombiana com o objetivo de reivindicar a memória do nativo, do autóctone através da arte. Josefina estudou com muito afinco a arte pré-colombiana e a formação da civilização americana. Foi uma intelectual que, assim como outros de sua época, se dedicou ao estudo da cultura americana, escrevendo diversos ensaios onde analisa a arte paraguaia e sua origem.

Apesar de ter aprendido diversas artes, a cerâmica foi o principal interesse de pesquisa de Plá. Mas, além de escrever sobre a cerâmica, (publicou o estudo La cerâmica popular paraguaya em 1994), também se transforma em uma das mais importantes ceramistas do país. O interesse pela cerâmica a aproxima da cultura e arte local, das suas tradições, da língua guarani, que aparece inclusive na sua escrita literária, dos processos de colonização históricos e contemporâneos e da cultura popular, que neste momento já é híbrida e heterogênea. Plá expõe, pela primeira vez, suas peças de cerâmica em 1931, onde exibiu seus primeiros e exitosos trabalhos em uma mostra conjunta com seu esposo Julián de La Herrería, em Madrid.

Considerando as diferentes contribuições de Josefina Plá para a discussão sobre a arte e cultura no Paraguai, Ángeles Mateo del Pino conclui que "no puede entenderse la cultura paraguaya contemporánea si no hacemos hincapié en la figura y obra de Josefina Plá" (2002, p. 12), e acrescenta que aqui a cultura é entendida como "el ejercicio de las facultades intelectuais y artística que, como en su caso, se manifiesta en una extensa y completa obra" (MATEO DEL PINO, 2002, pág.12). A autora hispano-paraguaia Josefina Plá (1903-1999) é uma grande sistematizadora da cultura paraguaia no século XX. Espanhola de origem, Josefina Plá chega ao Paraguai em 1927 e hoje é vista como uma das principais mediadoras culturais do país. Intelectual das artes e da literatura, dona de uma vasta produção artística, Josefina Plá foi poeta, contista, jornalista, artista plástica, dramaturga, tradutora, etc. Em 1955 foi designada pela UNESCO como organizadora da Primeira Mesa Redonda sobre o artesanato do Paraguai. Também, foi homenageada em 1979 pela Galeria de Artesanatos de Assunção pelos 50 anos de produção de cerâmica. Flecha (2011, p. 28) afirma que "la producción cultural paraguaya debe a Josefina mucho de lo que es." Seus primeiros trabalhos baseados na cultura paiaguá foram através da cerâmica mas, é na serigrafia onde aparece sua última oferenda a este povo:

Josefina, ya maestra de cerámica, consumada artista y escritora, desempolva diseños olvidados y publica, con Osvaldo Salerno, la serie de Diecisiete serigrafías Motivos Payaguá, en ellos reaviva dos mundos, el popular y el indígena, la imagen popular criolla de un ceramista moderno y la estética payaguá rescatada del contacto con los últimos supervivientes de este pueblo 
(CAPDEVILA, 2016, p. 32)

Figura representante da arte moderna paraguaia, Josefina Plá participou do grupo Arte Nuevo nos anos de 1950, composto por outros importantes representantes das artes plásticas paraguaias, como Olga Blinder, José Laterza Parodi e Lilí del Mónico. O grupo deu início a um período importante destas artes no país e teve a adesão de novos artistas locais. Mas, a série de serigrafias desenvolvida junto com Osvaldo Salerno ocorre somente nos anos de 1990. Inclusive, o texto La última ofrenda payagua, faz menção a uma exposição, apesar de não deixar claro de que se tratava de texto relativo ao trabalho desenvolvido com Osvaldo Salerno.

Assim, em La última ofrenda payagua a autora nos conta que seu primeiro contato com as artes indígenas do Paraguai ocorreu antes mesmo de ela chegar no país através de seu então namorado, o paraguaio Andrés Campos Cervera. Ele colecionava peças das etnias locais, entre elas, cuias de mate que eram vendidas no mercado velho de Assunção. Ao identificar algumas que possuíam desenhos diferentes dos que geralmente se encontrava, foi informado apenas de que eram obra de uma "velha matera" de Caacupé. No entanto, o que mais definiu o interesse de Plá pela estética destas cuias foi ter descoberto de que se tratava da estética paiaguá:

Y yo, sólo unos años después de su fallecimiento [o de Andrés Campos Cervera], en 1943, leí en la prensa indiferente la noticia de la muerte de Catalina (no recuerdo el apellido) "La última payagua", grabadora de mates em Caacupé... El mistério quedo desvelado. (PLÁ, 1999, p.15). ${ }^{5}$

Antes que qualquer coisa, a referência a tal episódio de sua vida não parece ter outro propósito que iluminar a história dos paiaguá. O termo "Arquivo" do Indicionário do contemporâneo (2018) alerta que a reflexão sobre o arquivo "[...] não pode, ou não deveria, pretender traçar uma linha demarcatória sólida entre um domínio público e um domínio íntimo, entre [...] um exercício de memória coletiva e institucional e um exercício de memória de si, de lembrança pessoal” (ANDRADE et. al., 2018, p.18) Neste texto da autora, como é possível observar, fica clara a perspectiva de trabalho com o arquivo que mistura o pessoal

\footnotetext{
${ }^{4}$ Josefina, quando já era professora de cerâmica, reconhecida artista e escritora, retira o pó de desenhos esquecidos e publica, com Osvaldo Salerno, a série Dezessete serigrafias Motivos Paiaguá, neles reaviva dois mundos, o popular e o indígena, a imagem popular crioula de um ceramista moderno e a estética paiaguá resgatada do contato com os últimos sobreviventes desse povo. (CAPDEVILA, 2016, p. 32, tradução própria).

${ }^{5} \mathrm{E}$ eu, só uns anos depois de seu falecimento [de Julián de la Herreria], em 1943, li na imprensa indiferente a notícia da morte de Catalina (não lembro do sobrenome) "La última payagua", gravadora de cuias de mates em Caacupé... O mistério foi desvendado. (PLÁ, 1999, p.15, tradução propria).
} 
com o público e vice-versa, uma vez que, tanto as memórias da autora estão a serviço de uma memória coletiva (a dos paiaguás), quanto a memória coletiva acaba por iluminar a memória individual de Plá.

Além disso, Josefina Plá também teve contato com a cultura paiaguá através de desenhos que encontrou em livros e revistas que um amigo lhe havia emprestado em 1950. No pequeno texto La última ofrenda payagua publicado em 1999 pelo jornal Correo Semanal, Josefina escreve que, por volta de 1950, o doutor Arturo Nagy, seu amigo lhe emprestou alguns livros e revistas nos quais ela encontrou desenhos paiaguá elaborados em pipas rituais que se conservavam em museus alemães. Os desenhos eram de cachimbos utilizados pelos autóctones paiaguá em rituais religiosos, para a surpresa da autora, esses cachimbos possuíam desenhos que lembravam a serpente do jardim do Éden presente na Bíblia Sagrada. Esses desenhos revelavam que essa comunidade, extinta, havia tido contato com os Jesuítas e que esses haviam lhes ensinado sobre a religião católica. Neste sentido, Plá demonstra um grande interesse em entender o porquê desta incorporação de símbolos da religião católica em objetos tão representativos para a cultura local como são os cachimbos de rituais. Os diálogos da igreja católica com a cultura nativa paraguaia era um dos grandes interesses de Josefina Plá. Ela escreve sobre esse tema quando trata da produção da cerâmica popular paraguaia analisando as mudanças que foram impostas pelos jesuítas nas missões em relação ao modo de produção da cerâmica. Também, na sua obra literária, encontramos no conto Gustavo (1945) uma referência ao encontro de padres católicos com ameríndios e como os símbolos da religião católica foram apropriados por eles. No conto, foram dadas imagens do niño Jesus aos nativos pelo padre Dositeo e estas foram coladas nas paredes das tendas.

Haja vista que as imposições religiosas tentaram moldar as culturas autóctones de acordo com os padrões europeus, os paiaguá mesmo sendo um povo que passava a maior parte do tempo em embarcações nos rios, não passaram incólumes pelo contato com os religiosos. No entanto, ainda que o contato pode ter gerado marcas na produção cultural deles, Josefina Plá destaca sua resistência à cristianização:

No es extraño que hasta los jesuitas maestros en la conversión no lograron acristianar a estos indígenas, reducido ya en su número a fines del siglo XVIII... Y estos diseños en las pipas rituales no sabemos si es un homenaje ingenuo o una burla refinada... Tarde para preguntar-lo (PLÁ, 1999, p.17) ${ }^{6}$.

\footnotetext{
${ }^{6}$ Não é estranho que até os jesuítas mestres na conversão não conseguiram cristianizar a estes indígenas, reduzidos já em seu número, no final do século XVIII... E estes desenhos nas pipas rituais não sabemos se é uma homenagem ingênua ou uma zombaria refinada... Tarde para se perguntar. (PLÁ, 1999, p.17, tradução própria)
} 
Toda a história sobre os paiaguá, que temos acesso, fala sobre uma comunidade que era preparada para enfrentar de forma planejada e organizada as investidas dos invasores, sejam eles brancos ou de outras comunidades autóctones. Por esse motivo, o questionamento de Plá no texto La última ofrenda payagua sobre o fato de que possivelmente os símbolos religiosos que estavam desenhados nos cachimbos rituais não eram um simples processo de aculturação, mas sim uma forma de deboche que os paiaguá faziam à religião católica, uma vez que, também não representam fielmente o imaginário católico. Em outra passagem do texto, Plá defende essa ideia tratando de uma crônica existente sobre os paiaguá:

Sabemos, sí, que los Payaguás de la colonia acudían los días de mercado semidesnudos de acuerdo a una moda para ellos estable, a trocar el producto de su actividad preferida, la pesca... Se los prohibió transitar así, y entonces se pintaron el traje sobre el cuerpo... ¿Muestra la ingenuidad otra vez, o de refinada ironia?... (PLÁ, 1999, p. 17) .

A cultura eurocêntrica sempre preferiu tratar os indígenas como inocentes e ingênuos que estão aí para serem ensinados sobre como se portar, como ser civilizados. Josefina Plá vai na contramão dessa perspectiva e percebe o "outro" como um ser de igual inteligência, capaz de zombar das imposições que não estavam de acordo com suas culturas. Essa 'refinada ironia' pode ter sido um dos fatores que fez com que a comunidade fosse tão atacada, porque por mais que a cultura tenha passado por uma reelaboração após o contato com os europeus, ela não incorpora a cultura imposta como algo natural que deve ser seguida sem questionamentos.

La última ofrenda payagua é um texto que se apresenta como um discurso de elegia, como um texto de homenagem a uma cultura que foi morta e enterrada sem os devidos louvores e reconhecimentos e que está sendo retomada para receber seu devido lugar no 'céu da história'. Josefina Plá arquiva a memória dos paiaguá ao reproduzir seus motivos na serigrafia e também quando imprime esses desenhos nas suas peças de cerâmica. Essa recuperação de informações, de memória, feitas por Josefina Plá é muito importante para a arte paraguaia, tanto os motivos paiaguá, quanto o barro que remete a ideia de terra e água, ajudam a reescrever a história do país.

Tendo em vista que, "o arquivo é um meio de armazenamento externo, que removeu a memória de dentro do ser humano e a tornou fixa e independente dos portadores vivos"

\footnotetext{
${ }^{7}$ Sabemos, sim, que os Paiaguá da colônia iam nos dias de mercado seminus de acordo com uma moda para eles estável, para trocar o produto de sua atividade preferida, a pesca... Os proibiram de transitar assim, e então pintaram roupas sobre o corpo... ¿Mostra de ingenuidade outra vez, ou de refinada ironia?... (PLÁ, 1999, p. 17, tradução nossa).
} 
(ASSMANN, 2016, p. 367), esse processo realizado por Plá, traz a luz no presente um conhecimento sobre o passado do país, fazendo com que a lembrança de seus mortos esteja presente na memória coletiva e na transmissão de saberes culturais para as gerações futuras.

\section{CONSIDERAÇÕES FINAIS}

Como uma importante pesquisadora da cultura paraguaia, Josefina Plá investigou a fundo a arte do país a que dedicou todo o trabalho de sua vida. Seu trabalho artístico de maior volume, e talvez de maior dedicação, foi a cerâmica. Além de investigar profundamente a cerâmica popular paraguaia, a autora/ artista também se dedicou a produzir peças que contavam de alguma forma a história cultural do Paraguai. Também, a cerâmica está representada em alguns de seus contos, seja quando se refere a peças específicas feitas em barro ou quando traz essa representação na tonalidade cor de barro da pele de personagens autóctones. Assim, diante do trabalho artístico e ensaístico de Plá, é possível perceber que a autora tinha uma visão crítica sobre o choque entre a cultura autóctone e a europeia e, ao realizar o seu trabalho com a cerâmica, encara as alteridades paraguaias como parte importante para a formação da identidade cultural do país, reafirmando seu passado autóctone.

Desse modo, o trabalho de Plá, que dialoga com os paiaguá, é um importante arquivo do passado e da história do Paraguai, pois "o arquivo contém embutida em si uma memória funcional na forma de memória de armazenamento, que é designada pelo nome 'herança cultural"'(ASSMANN, 2016, p.369), herança que leva as futuras gerações do país traços importantíssimos de sua identidade. É neste sentido, de recuperação de uma memória ausente, que o crítico de arte paraguaio Ticio Escobar resume o trabalho de Josefina Plá em torno de suas serigrafias de motivo paiaguá, último trabalho da artista e escritora:

La última obra de Josefina Plá desarrolla serigrafías basadas en la decoración de las calabazas y de las largas pipas shamánicas de los Payaguá que hoy ya no existen. Las palmas y las serpientes; los peces y los caimanes; los jaguares, las aves desconocidas y el surco enrevesado de las aguas que nombran siempre el río, son las figuras vivas de un mundo que se fue apagando ante la mirada ausente de nuestra propia historia y que fueron recuperadas desde la vista alerta de doña Josefina. Paradojas de una cultura que genera sus propios antídotos contra la destrucción que ella misma promueve: la estética payaguá, originariamente abstracta y geometrizante, toma la figuración de los españoles mestizos para representar su nueva vivencia asuncena; y, un siglo después, una española, mestizada por vocación y compromiso, retoma la imagen profusa de los antiguos artistas 
canoeros para nombrar ese mundo extraño y nuevo que ella eligió vivir. (ESCOBAR, 1999, s/p) ${ }^{8}$.

O fragmento deste texto/homenagem, escrito depois de dez anos do falecimento da escritora, reforça a importância de seu trabalho com as reminiscências da estética paiaguá, mas também, e com isto encerramos este estudo, anuncia que um novo arquivo que se forma a partir do trabalho de Josefina Plá, ou seja, mais uma herança cultural se constitui para as novas leituras sobre o país.

\section{REFERÊNCIAS}

AGAMBEN, G. O que é o contemporâneo? In: O que é o contemporâneo e outros ensaios. Trad. Vinícius Nicastro Honesko. Chapecó: Editora Argos, 2009. p. 55-73.

ANDRADE, A. et. al. Arquivo. In: PEDROSA, C. et. al. (Orgs) Indicionário do contemporâneo. Belo Horizonte: Ed. UFMG, 2018.

ASSMANN, A. Espaços da recordação: formas e transformações da memória cultural. Trad. Paulo Soethe. Campinas: Editora Unicamp, 2016.

BENJAMIN, W. Teses sobre o conceito de história. Tradução de Sérgio Paulo Rouanet. In: Walter Benjamin - Obras escolhidas. Vol. 1. Magia e técnica, arte e política. Ensaios sobre literatura e história da cultura. São Paulo: Brasiliense, 1987, p. 222-232.

CAMPOS, A. P. de. Breve noticia que dá o capitão Antonio Pires de Campos do gentio barbaro que ha na derrota da viagem das minas do Cuyabá e seu reconcavo. Revista Trimensal do Instituto HistoricoGeographico e Ethnographico do Brasil. Rio de Janeiro: Typ. de D. Luiz dos Santos, tomo XXV, 3․ Trimestre, 1862, p. 437-449.

CAPDEVILA, R. Julián y Josefina: de la indagación americanista al descubrimiento del arte popular paraguayo. In: Cuadernos Salazar \#4: Josefina. Assunção: Arte Nuevo, 2016, p. 28 32.

COSTA, M. de F. Entre Xarai, Guaicuru e Payaguá: Ritos de vida no pantanal. In: PRIORE, M. Del \& GOMES. F. (Orgs.). Os senhores dos rios. Amazônia, margens e histórias. Rio de Janeiro: Elsevier.2003

ESCOBAR, Ticio. Josefina Plá, a diez años de la partida de la gran artista. Disponible en:

\footnotetext{
${ }^{8}$ A última obra de Josefina Plá desenvolve serigrafias baseadas na decoração das cabaças e das compridas pipas xamânicas dos paiaguás que hoje já não existem. As palmas e as serpentes; os peixes e os jacarés; os jaguares, as aves desconhecidas e o traçado enrevesado das águas que nomeiam sempre o rio, são as figuras vivas de um mundo que se foi apagando diante do olhar ausente da nossa própria história e que foram recuperadas desde a vista alerta de Dona Josefina. Paradoxos de uma cultura que gera seus próprios antídotos contra a destruição que ela mesma promove: a estética paiaguá, originariamente abstrata e geometrizante, toma a figuração dos espanhóis mestiços para representar sua nova vivência assuncena; e um século depois, uma espanhola, mestiça por vocação e compromisso, retoma a imagem profusa dos antigos artistas canoeiros.
} 
In: https://www.ultimahora.com/josefina-pla-10-anos-la-partida-la-gran-artista-n186572.html Acesso em: 08 de abril de 2020.

FLECHA, V.-J. Prólogo. IN: ROCHE, A. A. Josefina Plá: una voz singular. Assunção: Grupo Editorial Atlas, 2011, p. 23-30.

JESUS, N. M. de. Os índios Payaguá: guerra e comércio na fronteira oeste da América portuguesa. In. Reitano, E.; Possamai, C, (Coords.). Hombres, poder y conflicto: Estudios sobre la frontera colonial sudamerica y su crisis. La Plata: Universidad Nacional de La Plata. Facultad de Humanidades y Ciencias de la Educación. Memoria Académica, 2015, p. 305320 .

MATEO DEL PINO, Á. De Canarias al corazón de América: Introducción. In: PLÁ, J. Los animales blancos y otros cuentos. Santiago: LOM, 2002.

PLÁ, J. La última ofrenda payagua. Correo semanal. Assunção, 14 de janeiro de 1999.

ROA BASTOS, A. Introducción. In: Las culturas condenadas. Asunción: Servilibros, 2011, p. 21- 29 .

Recebido: 16/09/2020

Aprovado: 20/01/2021 